\title{
Host Effect on the Genetic Diversification of Beet necrotic yellow vein virus Single-Plant Populations
}

\author{
Rodolfo Acosta-Leal, Becky K. Bryan, and Charles M. Rush
}

Texas AgriLife Research (Texas A\&M University System), Amarillo 79106.

Accepted for publication 1 July 2010.

\begin{abstract}
Acosta-Leal, R., Bryan, B. K., and Rush, C. M. 2010. Host effect on the genetic diversification of Beet necrotic yellow vein virus single-plant populations. Phytopathology 100:1204-1212.

Theoretical models predict that, under restrictive host conditions, virus populations will exhibit greater genetic variability. This virus response has been experimentally demonstrated in a few cases but its relation with a virus's capability to overcome plant resistance is unknown. To explore the genetic host effects on Beet necrotic yellow vein virus (BNYVV) populations that might be related to resistance durability, a wild-type virus isolate was vector inoculated into partially resistant $R z 1, R z 2$, and susceptible sugar beet cultivars during a serial planting experiment. Cloning and sequencing a region of the viral RNA-3, involving the
\end{abstract}

ABSTRACT pathogenic determinant $p 25$, revealed that virus diversity significantly increased in direct proportion to the strength of host resistance. Thus, whereas virus titers were highest, intermediate, and lowest in susceptible, $R z 1$, and $R z 2$ plants, respectively; the average number of nucleotide differences among single-plant populations was $0.8( \pm 0.1)$ in susceptible, 1.4 ( \pm 0.1$)$ in $R z 1$, and $2.4( \pm 0.2)$ in $R z 2$ genotypes. A similar relationship between host restriction to BNYVV root accumulation and virus genetic variability was detected in fields of sugar beet where these specific $R z l$ and $R z 2$-mediated resistances have been defeated.

Additional keywords: Benyvirus, Beta vulgaris, host adaptation, Polymyxa betae, quasispecies, resistance breakdown, rhizomania, virus fitness, zoospores.
Since Yarwood presented the first review about host effects on plant viruses more that 30 years ago (51), significant progress has been made to decipher the populational mechanisms of virus adaptation and host resistance breakdown. Recent studies indicate that viral adaptation to specific hosts, a phenomenon known as "host adaptation," may be affected by the genetic structure of the original virus population $(11,22)$, mode of experimental virus propagation (mechanical inoculation versus vector transmission) $(6,8,10,41)$, biology of the virus in relation to host range (i.e., generalist versus specialist) $(5,40)$, and selection pressure imposed by the potential host genotype $(34,48)$. Altogether, the emerging picture is that some viruses can rapidly adapt to different host environments. For instance, resistance-breaking (RB) variants can arise during the first encounter with a restrictive host $(4,20)$. Even mutations for systemic viral adaptations to nonhost plant species may occur spontaneously and become fixed in populations during initial host passages $(34,48)$. These studies also have revealed that parallel mutations are frequent among viral lineages overcoming the same host constraints, suggesting that viruses may have a limited number of evolutionary options for host adaptation (1). Despite their potential for rapid host adaptation, most plant viruses exhibit high genetic stability once they have achieved host and ecological adaptation (18). Purifying selection apparently plays a critical role in maintaining this genetic stasis $(12,16,18)$. To understand the practical implications of viral host adaptation, we explored the relationship between strength of host resistance and genetic diversity of a Benyvirus sp., Beet necrotic yellow vein virus (BNYVV).

BNYVV is the causal agent of rhizomania, a worldwide disease of sugar beet transmitted by the plasmodiophorid Polymyxa betae Keskin and characterized by taproot constriction, profuse lateral

Corresponding author: R. Acosta-Leal; E-mail address: racostaleal@hotmail.com

doi:10.1094/PHYTO-04-10-0103

(C) 2010 The American Phytopathological Society root proliferation, and leaf chlorosis (46). In addition to cultivated sugar beet (Beta vulgaris subsp. vulgaris), BNYVV naturally infects only a few species of the family Chenopodiaceae $(21,46)$. The infection cycle is initiated by viruliferous primary zoospores released from soilborne resting spores called sporosori. Then, after each rainfall and irrigation event during the growing season, the virus is dispersed by secondary zoospores repeatedly released from intracellular zoosporangia $(35,38)$. Upon BNYVV infection of epidermal cells in lateral rootlets, the virus moves to the cortex parenchyma, endodermis, and then xylem parenchyma cells, where it forms large clusters (45). From xylem parenchyma, BNYVV apparently accesses mature tracheary elements in order to be systemically transported. At least two unlinked loci, $R z 1$ and $R z 2$, which were originally found in $B$. vulgaris or its wild ancestor, B. maritima, respectively, confer partial resistance to rhizomania $(39,44)$. The mechanisms governed by these resistance genes are unknown but they markedly decrease virus content in infected tissue and suppress disease development. At the biochemical level, $R z 1$-mediated resistance is associated with differential expression of genes involved in pathogenesis and hormonemediated plant development $(9,27,43)$.

The genome of BNYVV is divided into four to five singlestranded, positive-sense RNA molecules. RNA-1 and -2 encode the essential elements for replication, encapsidation, and cellular translocation, whereas RNA-3, -4, and isolate-specific RNA-5 are translated into proteins involved in pathogenesis, vector transmission, and suppression of gene silencing $(28,33,46)$. p25 (RNA3 ) accounts for most of the rhizomania syndrome (47); is one of the most variable BNYVV genes, with strong positive selection acting on some of their amino acids (42); and encodes a determinant to overcome $R z 1(3,25)$. For these reasons, RNA-3 was chosen in the present work to analyze the genetic diversity of BNYVV after its passage through resistant $R z 1$ and $R z 2$ cultivars and a susceptible control.

One of the conclusions drawn from experimental evolution studies is that the genetic diversity of virus populations is in- 
versely correlated with fitness (31). Similarly, in a previous study, we observed that the intraisolate genetic diversity of BNYVV was several times higher in incompatible (i.e., low virus fitness) than compatible (i.e., high virus fitness) BNYVV-sugar beet interactions, where $R z l$ was defeated by emerging $\mathrm{RB}$ variants (2). Based on this finding, we decided to explore the genetic plant-to-plant diversification of a wild type (WT) (i.e., virulent in susceptible but avirulent in resistant plants) BNYVV isolate during its incompatible stage and under different host selection pressures. Our working hypothesis was that the extent of BNYVV diversification occurring before the emergence of $\mathrm{RB}$ variants is host dependent and might be an indicator of plant resistance durability.

\section{MATERIALS AND METHODS}

The serial host-planting experiment. BNYVV-resistant sugar beet cultivars carrying the dominant $R z 1$ or $R z 2$ alleles and a susceptible $(r z 1 r z 2)$ control were grown in individual pots. Twelve plants of each cultivar were seeded into a commercial potting soil mix containing $\approx 2 \mathrm{~g}$ of field soil infested with a WT BNYVV $(1,2)$. As negative controls, the same number of plants of each cultivar was seeded into uninfested potting soil mix. The initial inoculum consisted of BNYVV-infested soil collected from the rhizosphere of susceptible plants cultivated in a commercial field near Climax, MN (Clx isolate, accession no. EU480492). As indicated by real-time reverse-transcription polymerase chain reaction (RT-PCR) detection assays (data not included), the original soil inoculum was free of Beet soilborne mosaic virus, another Benyvirus sp. occasionally found in this region. Root tissue was harvested 12 to 14 weeks after planting; then, $\approx 50 \%$ of the soil/root mixture from each pot was used as inoculum for the consecutive host planting. By following this experimental approach, it was expected that viruliferous sporosori of $P$. betae from the previously infected plants would be the sources to infect the following test plants, thereby creating virus lineages. However, the possibility that plants in the consecutive host planting also were infected by virions remaining from the original inoculum, rather than by virions released from the previously infected plants, was not discarded. Therefore, truly serial host passages were not guaranteed but this approach was preferred over mechanical inoculation of the virus from passage to passage because it more closely mimics what normally happens in the field from one cultivation cycle to the next.

Total RNA extractions from root tissue. Root tissue from the three host genotypes was collected on the same day for comparative purposes and stored in $2-\mathrm{ml}$ microfuge tubes at $-80^{\circ} \mathrm{C}$ until processing. Total RNA extractions were performed from $0.1 \mathrm{~g}$ of frozen plant tissue according to the RNAqueous-Mini kit (Ambion Inc., Austin, TX) protocol with modifications described previously (2) or the RNeasy Plant Mini Kit (Qiagen Inc., Valencia, CA) protocol as described by Acosta-Leal et al. (1). Both protocols gave similar reading of relative viral RNA content and did not affect the genetic composition of viral populations (data not shown) but the second protocol rendered more total RNA per sample and was more practical.

Real-time RT-PCR viral RNA quantifications. BNYVV titers in $20 \mathrm{ng}$ of total RNA per sample were estimated by relative realtime RT-PCR quantifications using $18 \mathrm{~S}$ ribosomal RNA as the endogenous control and a minimally infected sample as the calibrator according to the cycle threshold $(\Delta \Delta \mathrm{Ct})$ method (29). This procedure determines the number of times a target RNA is above or below the calibrator sample that is included as a second reference. Because we used a calibrator sample with the lowest detectable amount of viral RNA $(\approx 100$ molecules/ng of total RNA previously estimated by absolute quantification), all positive test samples were those with a virus titer above the calibrator sample. Primers 50F (5'-CCGTTTTCCACAGACACTAACTATGTA-3') and 51R (5'-TGCTAACCCTGAATCAGTTAAAGTACTT-3') plus TaqMan probe NYCP (6FAM-TGCACTTGTGTTATATGTTAATCTGTCTGACCCAG-TAMRA) were incorporated in one-step RT-PCR to target the core of the coat protein gene in RNA-2. Real-time reactions were performed by an ABI Prism 7000 system (Applied Biosystems Inc., Foster City, CA) using the following parameters: reverse transcription at $48^{\circ} \mathrm{C}$ for $30 \mathrm{~min}$, reverse transcriptase inactivation at $95^{\circ} \mathrm{C}$ for $10 \mathrm{~min}$, and amplification during 40 cycles of denaturing at $95^{\circ} \mathrm{C}$ for $15 \mathrm{~s}$ and annealing at $60^{\circ} \mathrm{C}$ for $1 \mathrm{~min}$.

RT-PCR, cloning, and sequencing. First-strand cDNA was synthesized using the Omniscript reverse-transcriptase kit (Qiagen Inc.) according to the manufacturer's recommendations. Total RNA $(1.0 \mu \mathrm{g})$ was denatured at $65^{\circ} \mathrm{C}$ for $5 \mathrm{~min}$ before annealing with $0.5 \mu \mathrm{g}$ of oligo- $\mathrm{dT}_{12-18}$ primer and incubating at $37^{\circ} \mathrm{C}$ per $1 \mathrm{~h}$ for cDNA polymerization. PCR was performed in a second tube using Platinum Taq high fidelity polymerase (Invitrogen Inc., Carlsbad, CA) and $5.0 \mu \mathrm{l}$ of the reversetranscription product. The primers and PCR conditions used with samples from the first host planting were as follows: forward, F29 (5'-TTAATCCAAGTACCTCGTCT-3'), and reverse, R30 (5'TTGAAATTGTGATAACTCTAA-3') or R32 (5'-CATGTAACCGGCTGTGGAACC-3') primers were added at a final concentration of $0.5 \mu \mathrm{M}$ each and the rest of the reagents were incorporated at concentrations recommended by the manufacturer. DNA amplification occurred during 30 cycles of denaturing at $94^{\circ} \mathrm{C}$ for $30 \mathrm{~s}$, annealing at $55^{\circ} \mathrm{C}$ for $30 \mathrm{~s}$, and extending at $68^{\circ} \mathrm{C}$ for $1 \mathrm{~min}$. Samples from the second and third host plantings were amplified with primers NYP25-F1 (5'-TTCCTGACCGACCAAATCCA-3') and NYP25-R1 (GTAAACGGACGGGAACACCA-3') during 30 cycles of denaturing at $94^{\circ} \mathrm{C}$ for $30 \mathrm{~s}$, annealing at $56^{\circ} \mathrm{C}$ for $30 \mathrm{~s}$, and extending at $68^{\circ} \mathrm{C}$ for $1 \mathrm{~min} 30 \mathrm{~s}$. The purpose of increasing the amplicon size from these host plantings was to maximize the amount of genetic sequence information.

From some randomly selected samples where virus infection was detected by electrophoresis, amplified fragments were cleaned using the QIAquick kit (Qiagen Inc.), quantified by spectrophotometry, and recombined with pCR-Blunt (Invitrogen Inc.) vector. Plasmid DNA was extracted from individual clones using the QIAprep Spin Miniprep Kit (Qiagen, Inc.) and sequenced in both directions by commercial companies (Polymorphic DNA Technologies, Alameda, CA or Beckman Coulters Genomics, Danvers, MA) to analyze the genetic composition of the infecting populations. To minimize experimental error, cloned DNA was never exposed to mutagens (i.e., UV or ethidium bromide) and bacterial colonies were not replated. The artificial mutations that could have been introduced during cDNA synthesis, amplification, and cloning were estimated to be $<1 \times 10^{-4}$ mutations per sequenced bases. This conservative estimation was based on the mutation frequency detected in the most homogeneous population, the original inoculum. Therefore, any mutation frequency detected above this threshold was considered as an effect of the treatment.

Phylogenetic and populational analyses of viral RNA sequences. The basic processing of cDNA sequences, such as assembling, correction, and alignment, were performed with the Lasergene package v8 (Dnastar Inc., Madison, WI), and chromatograms were inspected with Sequence Scanner v1.0 (Applied Biosystems Inc.) to verify the presence of mutations. Sequence alignments created in MegAlign were saved in Fasta format for exporting into different applications used in this study. Phylogenetic trees were reconstructed by the neighbor-joining algorithm using Kimura's two-parameter model as implemented in MEGA 3.1 (26). This approach was preferred to other substitution models based on the low sequence divergence expected in progenies of a known ancestor after serial host plantings. Counting of polymorphic sites, mutations of different types, and haplotypes was performed by DnaSP v4.10.7 (37). 
Nucleotide diversity $(\pi)$, defined as "the average number of nucleotide differences per site between any two randomly chosen sequences from a population (19)," is conditioned by both the frequency of each sequence in a population and the pairwise nucleotide differences between them. Each different virus sequence from a clone was considered a haplotype during the analyses of populational differentiation by the $\mathrm{F}_{\mathrm{ST}}$ index of dissimilarity (50) as implemented in Arlequin v.3.11 (13) for haplotypic data. $\mathrm{F}_{\mathrm{ST}}$ measures the degree of differentiation between two putative subpopulations by comparing the agreement between two haplotypes drawn at random from each subpopulation with the agreement obtained when the haplotypes are taken from the same subpopulation. Depending on the analyses, the compared populations were at the level of single-plant or host genotype for each host planting. The parameters were 16,000 permutations of haplotype pairwise comparisons, considering only the frequency of haplotypes ("use conventional $F$-statistics" option in Arlequin) or the frequency plus genetic distances among haplotypes ("compute distance matrix" option). Tests of neutrality in the evolving virus populations were performed with the DnaSP package following the ratio of nonsynonymous substitutions per nonsynonymous sites versus synonymous substitutions per synonymous sites $\left(\mathrm{d}_{\mathrm{NS}} / \mathrm{d}_{\mathrm{S}}\right)$ for the $p 25$ and $N$ open reading frames (ORFs). The Nei-Gojobori method, as implemented in DnaSP v4.10.7 (37), was used to identify neutral $\left(\mathrm{d}_{\mathrm{NS}}=\mathrm{d}_{\mathrm{S}}\right)$, positive $\left(\mathrm{d}_{\mathrm{NS}}>\mathrm{d}_{\mathrm{S}}\right)$, or purifying $\left(\mathrm{d}_{\mathrm{NS}}<\mathrm{d}_{\mathrm{S}}\right)$ selection in each virus population.

\section{RESULTS}

Genetic composition of the original BNYVV population. The original soil inoculum was infested with a BNYVV population composed of one predominant haplotype, named hO, encoding the WT amino acid $\mathrm{A}_{67} \mathrm{C}_{68} \mathrm{D}_{135}$ p25-motif. Previous studies indicate that BNYVV strains carrying this p25 signature were virulent in $r z 1 r z 2$ but avirulent in the analyzed $R z 1$ and $R z 2$ sugar beet genotypes $(3,25,32)$. By contrast, $R B$ variants able to overcome $R z 1$ encoded valine at position $67(1,3,25)$, whereas the capability to cause rhizomania in $R z 2$ plants has not been associated to any specific mutation. No haplotype other than hO was detected out of 10 clones sequenced from the original WT BNYVV population.

Diversification and survival of BNYVV from planting to planting. In each of three serial host plantings, 12 inoculated and 12 noninoculated plants of each sugar beet genotype were grown and harvested at 12 to 14 weeks after planting, to determine virus content in root tissue. Except for one noninoculated $R z 2$ plant that may have been accidentally inoculated or contaminated during the first planting, no BNYVV was detected by real-time RT-PCR in the rest of the negative controls. The virus titer in each inoculated plant that survived the experiment (i.e., one or two plants of each genotype died during the course of the experiment) is presented in Figure 1, and the average titers by host genotype and host planting are in Figure 2C. Only in resistant sugar beet did virus titer decrease from planting to planting to the point where the percentage of infected plants was, by the end of the experiment, 70 and 37 in $R z 1$ and $R z 2$ genotypes, respectively. Because virus titer in the susceptible controls was similar from planting to planting, this trend in resistant plants indicated that the reload of viable virus into the soil from the previously infected plants played a significant role in the amount of inoculum available for the following host planting, and that host resistance significantly affected this variable.

Consensus DNA sequencing (i.e., sequences derived directly from RT-PCR amplicons) of each single-plant isolate revealed that some carried a mutation undetected in the original WT virus population. Each of these mutations is represented in Figure 1 as an asterisk above the carrying isolate, and additionally described in Table 1 according to its genomic position from the $5^{\prime}$ to $3^{\prime}$ ends. None of these mutations was passed to the progeny during the following host planting, which suggests that virus lineages were rarely, if ever, created during the course of the experiment. Significantly, 1.8 to 4.9 times more mutations were detected in resistant than susceptible plants (Table 2). This high frequency of mutations was more prevalent during the second host planting and in $R z 2$ than $R z 1$ plants. By the third host planting, all of the six sequenced isolates from $R z l$ plants were WT, which suggests that, at this stage, the low content of competent mutants in the inoculum was depleted or at very low frequency in the resting spores of $P$. betae. Consequently, by the third planting, all of the successful infections may be caused by the still-available hO haplotype.

In total, 18 mutations were detected in the 69 sequenced singleplant BNYVV isolates (Table 1). Of these, 11 were spread along the $p 25$ and $N$ genes. From those in $p 25$, six were nonsynonymous and two were synonymous but no selection was evidenced based on the $\mathrm{d}_{\mathrm{NS}} / \mathrm{d}_{\mathrm{S}}$ ratio of 0.97 . This observation favors the hypothesis that mutants were moving into the progenies mainly by random genetic drift. The same mutation at nucleotide positions $503,673,1,026$, and 1,184 were observed in more than one isolate but they were from the same host planting, which suggests that they were transmitted from the same pool of haplotypes composing the original inoculum. Interestingly, two different amino acid substitutions were observed at position 68 of p25 (Table 1), corroborating the hypervariable nature of this site.

Relationship between interplant BNYVV diversity and host resistance. Four to five single-plant populations chosen at random from each host genotype of the first and second host planting were analyzed by cloning and sequencing a fragment of the viral RNA-3. The number of sequenced clones was 7 to 25 per virus population. In total, 385 clones were sequenced (114 sequences of 975 nucleotides long and 271 sequences of 1,413 nucleotides long from first and second host planting, respectively), and the genetic diversity estimated from these data is presented in Table 3 . The nucleotide diversity ( $\pi=$ number and frequency of polymorphic nucleotides) was the highest in $R z 2$ (0.0015 to 0.0019), intermediate in $R z 1$ ( 0.0010 to 0.0015$)$, and lowest in susceptible plants $(0.00063$ to 0.00069$)$, which agrees with the same trend observed by consensus sequencing (Table 2). This characterization of the intrapopulational genetic composition was valuable to determine the statistical populational differentiation between isolates and host genotypes. Thus, the genetic distances between single-plant isolates from the same host planting and host genotype were the largest in $R z 2$, intermediate in $R z l$, and lowest in susceptible plants (Fig. 2A and B). Based on the $\mathrm{F}_{\mathrm{ST}}$ index of dissimilarity, the totality of pairwise comparisons between three artificial populations composed of the sequenced individuals from each host genotype were statistically different by considering both the frequency of haplotypes and genetic distances between them $(P<0.001)$. The greatest genetic differentiation was between susceptible versus $R z 2$ and $R z l$ versus $R z 2$. Overall, the levels of genetic differentiation between BNYVV isolates were inversely related to the content of viral RNA in root tissue (Fig. 2, compare $\mathrm{C}$ versus $\mathrm{A}$ or $\mathrm{B}$ ).

Phylogenetic structure of BNYVV haplotypes. In all, 34 and 117 haplotypes were identified out of the 114 and 271 sequenced clones from the first and second host plantings, respectively. An exhaustive phylogenetic analysis was conducted only with the haplotypes from the second host planting but similar results (data not included) were obtained with the smaller set of haplotypes from the first host planting. In both cases, the haplotypes were phylogenetically structured according to the source plant, especially those isolated from resistant plants. To identify the predominant haplotypes in each single-plant population from the second host planting, the frequency of each haplotype was graphically represented by piled dots (Fig. 3). This type of phylogenetic landscaping showed that hO, same as hOO1, was 

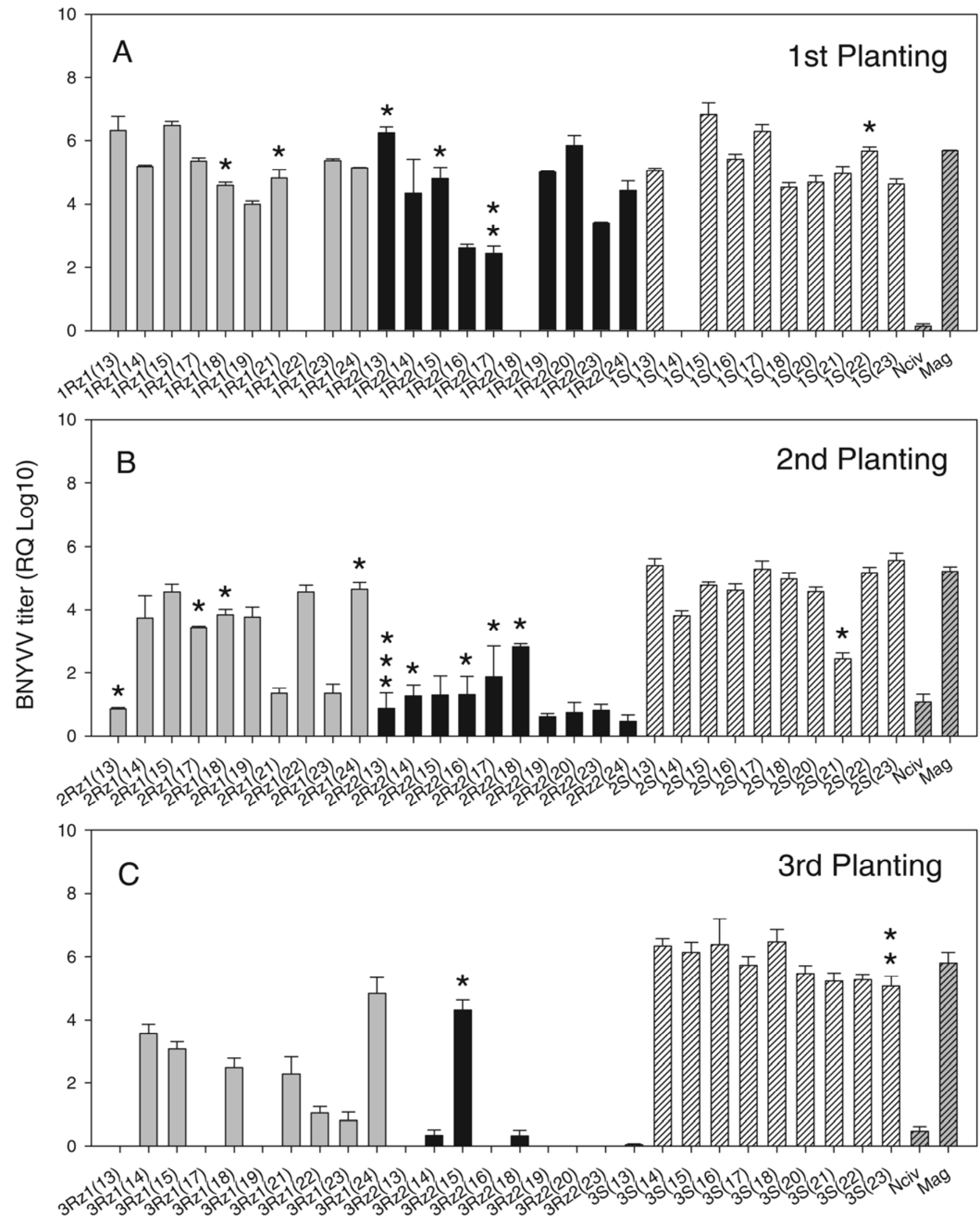

Single-plant isolates

Fig. 1. Relative quantification of Beet necrotic yellow vein virus (BNYVV) RNA in susceptible (S) and resistant (Rz1 or $R z 2)$ sugar beet plants exposed to the same original soil inoculum containing a predominant wild-type BNYVV haplotype and monitored after three serial plantings. Each asterisk represents a mutation detected in the consensus sequence of the corresponding single-plant isolate. 
the predominant haplotype in the majority of the analyzed plants, and a trend to replace it was revealed in resistant plants. Thus, whereas hO predominated in all susceptible plants, which corroborated the high genetic stability of BNYVV in this compatible plant-virus interaction, it was undetected or became a minor haplotype in 4 of 10 resistant plants. In $R z 1$ plants, three of five virus populations generated a differentiated clade (encircled subpopulations) that caused a marked reduction in the relative frequency of hO without its complete replacement. By contrast, each of the five $R z 2$ plants generated a clade that diverged from the original population. Complete replacement of hO occurred in two of them. Shifting of the original hO haplotype to another was accompanied by the generation of a spectrum of mutants, closely
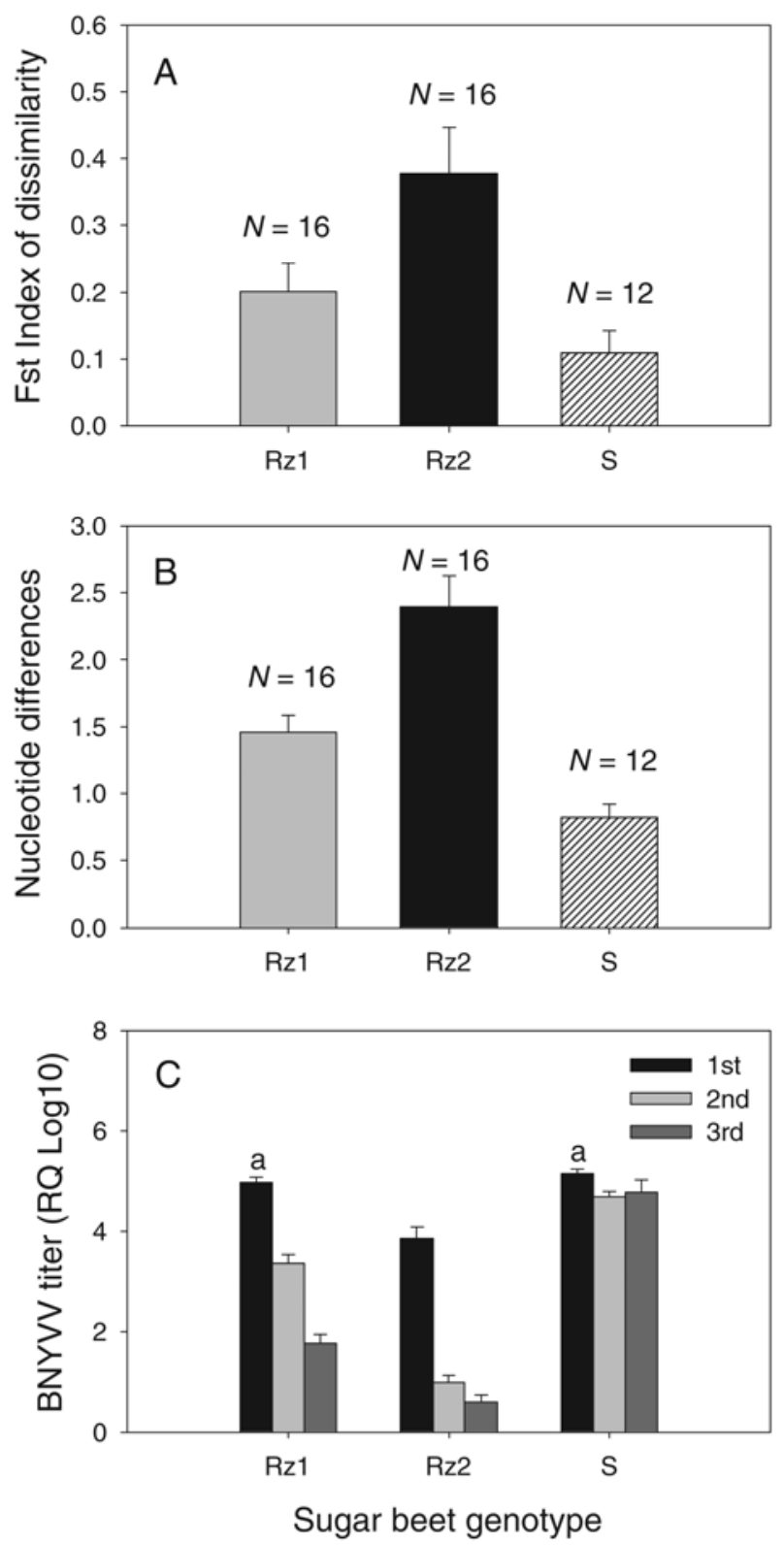

Fig. 2. Relationship between plant resistance to Beet necrotic yellow vein virus (BNYVV) accumulation in root tissue and interplant virus diversity. Interplant diversity was estimated between all possible pairwise comparisons $(N)$ of eight (susceptible control) or nine (resistant plants) single-plant populations by $\mathbf{A}$, the $\mathrm{F}_{\mathrm{ST}}$ index of dissimilarity (values 0 to 1 ) and $\mathbf{B}$, the average number of nucleotide differences according to Arlequin v.3.11 (15). C, Average virus titers from data presented in Figure 1. Statistical comparisons were performed only between plant genotypes from the same planting assay. Except for susceptible versus $R z l$-plants from the first planting (treatments with the same letter), the rest of the treatments were statistically different (Tukey, $P<0.001$ ). related to each other by descent. The predominant haplotypes that arose in resistant plants were always those that were most closely related to hO, rather than any of the minor haplotypes composing the respective clade (data not included). Occasionally, a haplotype that predominated in a resistant plant was also detected as a minor haplotype infecting a susceptible plant, such as h056 from 2Rz2(16) and h036 from 2Rz2(14). In the first case, the susceptible source is indicated in Figure 3. In the second case, h036 was identical to $\mathrm{h} 34$ from the $1 \mathrm{~S}(23)$ population not included in Figure 3. This observation supports the hypothesis that low-frequency haplotypes contained in the original inoculum, which was collected from susceptible plants, were most likely the founders of populations infecting resistant plants.

Host effect on the genetic diversity of BNYVV in the field. To determine whether a similar host genotype-virus diversity relationship was taking place in the field, viral isolates extracted from symptomatic $R z 1, R z 2$, and susceptible plants collected from southern Minnesota during 2007 and 2009 were consensus sequenced on the same RNA-3 region. Isolates from $R z 1$ plants encoded the $\mathrm{RB} \mathrm{V}_{67} \mathrm{C}_{68} \mathrm{p} 25$-motif whereas isolates from $R z 2$ and susceptible plants encoded alanine at position 67 (data not shown). Therefore, the differentiation between WT versus RB variants overcoming $R z 2$ was based only on the capability of the later to cause severe rhizomania in plants carrying the molecular marker for $R z 2$ (data not shown). The lowest nucleotide diversity was among WT isolates from susceptible plants $(\pi=0.00038 \pm$ 0.0002 ), with an average nucleotide difference between isolates of $0.50 \pm 0.2$ (Table 4). From this baseline, the genetic diversity was approximately two and five times greater between RB isolates from $R z 1$ and $R z 2$ symptomatic plants, respectively. These values agree with the data obtained through the serial host-planting experiment (Table 2) and indicate that the type and strength of sugar beet resistance against BNYVV accumulation also affect the diversification of BNYVV in the field.

Phylogenetic comparisons among greenhouse and field singleplant isolates included in this study revealed that the $\mathrm{A}_{356} \mathrm{U}$ mutation detected in the $2 \mathrm{Rz} 2(14)$ population (Table 1) also was present in two field isolates from symptomatic $R z 2$ plants (data not included). In the same way, the nonsynonymous $\mathrm{G}_{648} \mathrm{U}$ nucleotide substitution detected in $3 \mathrm{~S}(23)$ was found in two other symptomatic $R z 2$ plants from the field. Whether these mutations have an adaptive value in the $R z 2$ host environment is still under investigation.

TABLE 1. Mutations detected by consensus sequencing of a Beet necrotic yellow vein virus RNA-3 fragment after passage through susceptible (S) or resistant $(R z 1$ or $R z 2)$ sugar beet plants

\begin{tabular}{|c|c|c|c|}
\hline $\begin{array}{l}\text { Consensus } \\
\text { mutation }\end{array}$ & Single-plant population & RNA-3 region ${ }^{a}$ & Mutation type \\
\hline$\overline{\mathrm{A}_{356} \mathrm{U}}$ & 2Rz2(14) & 5'-UTR & Noncoding \\
\hline $\mathrm{U}_{397} \mathrm{G}$ & 1Rz2(17) & 5'-UTR & Noncoding \\
\hline $\mathrm{U}_{438} \mathrm{C}$ & 1Rz2(13) & 5'-UTR & Noncoding \\
\hline $\mathrm{C}_{503} \mathrm{~A}$ & 2Rz1(24), 2Rz2(13) & p25 cistron & $\mathrm{R}_{20} \mathrm{~S}$ \\
\hline $\mathrm{A}_{634} \mathrm{G}$ & $1 \operatorname{Rz} 1(18)$ & p25 cistron & Synonymous \\
\hline $\mathrm{U}_{647} \mathrm{C}$ & $1 R z 1(21)$ & p25 cistron & $\mathrm{C}_{68} \mathrm{R}$ \\
\hline $\mathrm{G}_{648} \mathrm{U}$ & $3 \mathrm{~S}(23)$ & p25 cistron & $\mathrm{C}_{68} \mathrm{~F}$ \\
\hline $\mathrm{U}_{673} \mathrm{C}$ & 2Rz2(13), 2Rz2(18) & p25 cistron & Synonymous \\
\hline $\mathrm{C}_{846} \mathrm{G}$ & 2Rz1(13) & p25 cistron & $\mathrm{T}_{134} \mathrm{~S}$ \\
\hline $\mathrm{C}_{1026} \mathrm{U}$ & 2Rz2(13), 2Rz2(17) & p25 cistron & $\mathrm{S}_{194} \mathrm{~F}$ \\
\hline $\mathrm{C}_{1084} \mathrm{~A}$ & $1 \operatorname{Rz} 2(17)$ & $p 25-N$ overlap & $\mathrm{D}_{213} \mathrm{E}, \mathrm{T}_{11} \mathrm{~K}$ \\
\hline $\mathrm{U}_{1184} \mathrm{C}$ & $2 \operatorname{Rz} 2(16), 2 \mathrm{~S}(21)$ & $N$ cistron & Synonymous \\
\hline $\mathrm{U}_{1213} \mathrm{G}$ & 2Rz1(17) & $N$ cistron & $\mathrm{F}_{54} \mathrm{C}$ \\
\hline $\mathrm{U}_{1220} \mathrm{C}$ & $1 \mathrm{~S}(22)$ & $N$ cistron & Synonymous \\
\hline $\mathrm{A}_{1260} \mathrm{U}$ & $3 \mathrm{~S}(23)$ & 3'-UTR & Noncoding \\
\hline $\mathrm{U}_{1298} \mathrm{C}$ & $3 R z 2(15)$ & 3'-UTR & Noncoding \\
\hline $\mathrm{U}_{1399} \mathrm{C}$ & 2Rz1(18) & 3'-UTR & Noncoding \\
\hline $\mathrm{U}_{1452} \mathrm{C}$ & $1 \mathrm{Rz} 2(15)$ & 3'-UTR & Noncoding \\
\hline
\end{tabular}

a Open reading frame of the $N$ cistron overlaps with the $3^{\prime}$ end of $p 25$ cistron (23). UTR = untranslated region. 


\section{DISCUSSION}

By comparing the genetic structure of BNYVV populations generated in susceptible and resistant plants from the same parental WT population, we found that the same WT haplotype predominated in most of the susceptible plants, which is consistent with the high genetic stability of BNYVV observed in the field $(2,24)$. By contrast, resistant plants were more frequently infected by different predominant haplotypes that might have been randomly picked from the original soil inoculum. Once the test plants were infected by a founder haplotype, spontaneous mutations in the progeny gave place to a spectrum of mutants closely related to each other by descent (17); however, vertical transmission was not detected for any of these mutants. In addition, the data presented in this work demonstrate that virus diversification was directly proportional to strength of plant resistance to virus accumulation in root tissue. This virus behavior also occurred in the field and may reflect the evolutionary BNYVV potential for host adaptation. To our knowledge, this is the first empirical demonstration of a relationship between the strength of plant resistance to virus accumulation and the populational genetic diversity of a plant virus.

Most, if not all, of the 18 consensus mutations detected in this study apparently moved into the infecting populations by random genetic drift $\left(\mathrm{d}_{\mathrm{NS}} / \mathrm{d}_{\mathrm{S}}=0.97\right)$; however, this mechanism by itself does not explain the differential BNYVV diversification. For this purpose, the intraplant virus nucleotide diversity $(\pi)$ could be more informative because a greater intraplant $\pi$ was detected in resistant than susceptible sugar beet plants. Thus, the differential intraplant virus variability might have translated into a proportional plant-to-plant virus diversification. However, because none of the emerging mutants was detected in the following generation, their contribution to the effective virus diversification is questionable. A more feasible possibility was revealed by the phylogenetic landscaping analysis (Fig. 3). It showed that predominant haplotypes in resistant plants were more closely related to hO than any other haplotype. Therefore, it is possible that negative selection against hO operating proportionally to resistance strength was the main evolutionary mechanism that gave place to the differential BNYVV diversification.

The differential responses between resistant and susceptible plants during the serial planting experiment (Fig. 1) indicate that reloading of the soil with viruliferous $P$. betae was important in maintaining the high incidence of BNYVV infections observed in susceptible plants. Therefore, the decreasing virus occurrence from passage to passage in resistant plants could be explained by at least two possible nonexclusive hypotheses. First, the amount of infectious particles carried on by the vector from the source plant into the soil and then from the soil into the following test plant may have been drastically reduced. Tuitert et al. (49) demonstrated that partial sugar beet resistance to BNYVV accumulation in lateral roots decreases the proportion of viruliferous resting spores of $P$. betae without affecting the reproduction of the vector. Therefore, acquisition of BNYVV could have been reduced in the $R z 1$ and $R z 2$ source plants according to their virus titer. Second, most virus mutants may have had a reduced capacity to survive out of the plant or be transmitted by $P$. betae. At present, no evidence supports this possible scenario but further studies comparing the genetic composition of virus populations extracted from source plants versus viruliferous zoospore suspensions might shed light on this aspect.

The fact that none of the mutants was vertically transmitted through the same lineage was an unexpected finding but, at the same time, it provides a more realistic idea about the chances a BNYVV mutant might have to predominate in the crop from season to season. To be successful, a BNYVV mutant most likely needs to be positively selected and, moreover, be in numerical superiority against the parental WT population residing in the soil (12). Thus, the type of relationship between size and complexity of BNYVV populations in restrictive host environments seems to be a suitable parameter to assess the risk of resistance breakdown. Further studies in this direction may identify the optimal sizecomplexity ratio of BNYVV populations required to generate and fix adaptive mutations, and avoid a mutational meltdown or a Muller's ratchet effect $(12,18,31)$. Likewise, identification of host conditions that prevent the virus from reaching its optimum sizecomplexity ratio will be beneficial for crop improvement.

The size of a virus population changes during the infection period but, in some plant-virus interactions, such as sugar beetBNYVV, overall virus accumulation is greater in compatible than incompatible combinations (2). This implies that, for practical purposes, BNYVV titer reflects its fitness to a specific host environment. According to studies using cell cultures infected in vitro, viral genetic diversity remains low during the phase of maximum fitness and increases with the loss of virus fitness (31).

TABLE 3. Host effect on the genetic diversity of Beet necrotic yellow vein virus estimated by cloning and sequencing a fragment of the viral RNA-3 from 26 single-plant virus populations

\begin{tabular}{lcccc}
\hline $\begin{array}{l}\text { Planting, } \\
\text { host genotype }\end{array}$ & $\begin{array}{c}\text { No. of } \\
\text { isolates }\end{array}$ & $\begin{array}{c}\text { Sequenced } \\
\text { clones }^{\mathrm{a}}\end{array}$ & $\begin{array}{c}\text { MF } \\
\left(\times 10^{-3}\right)^{\mathrm{b}}\end{array}$ & $\begin{array}{c}\pi \\
\left(\times 10^{-3}\right)^{\mathrm{c}}\end{array}$ \\
\hline First & & & & \\
$R z 1$ & 4 & 32 & $14 / 31,168(0.45)$ & $1.49 \pm 0.5$ \\
$R z 2$ & 4 & 40 & $12 / 38,960(0.31)$ & $1.46 \pm 0.6$ \\
$r z 1 r z 2$ & 4 & 42 & $9 / 40,908(0.22)$ & $0.69 \pm 0.3$ \\
Second & & & & \\
$R z 1$ & 5 & 80 & $41 / 113,040(0.36)$ & $1.00 \pm 0.2$ \\
$R z 2$ & 5 & 114 & $87 / 161,082(0.54)$ & $1.88 \pm 0.4$ \\
$r z 1 r z 2$ & 4 & 77 & $27 / 108,801(0.25)$ & $0.63 \pm 0.1$ \\
\hline
\end{tabular}

a Numbers of aligned sequences used to estimate the genetic diversity.

${ }^{\mathrm{b}}$ Mutation frequency $(\mathrm{MF})=$ total number of nucleotide substitutions over total number of sequenced nucleotides.

c Nucleotide diversity $(\pi)$ based on the Kimura $2 \mathrm{P}$ model \pm standard error estimated by 500 replicates bootstrapping using MEGA 3.1 (26).

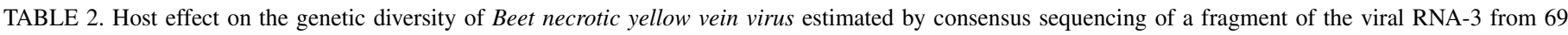
single-plant virus populations

\begin{tabular}{|c|c|c|c|c|c|}
\hline Host gene & Variable $^{\mathrm{a}}$ & First planting & Second planting & Third planting & Total \\
\hline \multirow[t]{3}{*}{$R z 1$} & No. of isolates & 10 & 7 & 6 & 23 \\
\hline & $\operatorname{MF}\left(\times 10^{-3}\right)$ & $2 / 11,872(0.17)$ & 4/9,807 (0.41) & $0 / 8,196(0.0)$ & $6 / 29,875(0.20)$ \\
\hline & $\pi\left(\times 10^{-3}\right)$ & $0.3 \pm 0.2$ & $0.9 \pm 0.4$ & 0.0 & $0.4 \pm 0.2$ \\
\hline \multirow[t]{3}{*}{$R z 2$} & No. of isolates & 9 & 8 & 1 & 18 \\
\hline & $\operatorname{MF}\left(\times 10^{-3}\right)$ & $4 / 10,605(0.38)$ & $7 / 10,413(0.67)$ & $1 / 1,370(0.73)$ & $12 / 22,388(0.54)$ \\
\hline & $\pi\left(\times 10^{-3}\right)$ & $0.7 \pm 0.3$ & $1.4 \pm 0.5$ & $\mathrm{n} / \mathrm{c}^{\mathrm{b}}$ & $1.1 \pm 0.3$ \\
\hline \multirow[t]{3}{*}{$r z 1 r z 2$} & No. of isolates & 9 & 10 & 9 & 28 \\
\hline & $\mathrm{MF}\left(\times 10^{-3}\right)$ & $1 / 10,878(0.09)$ & $1 / 13,814(0.07)$ & $2 / 12,320(0.16)$ & $4 / 37,012(0.11)$ \\
\hline & $\pi\left(\times 10^{-3}\right)$ & $0.2 \pm 0.2$ & $0.1 \pm 0.1$ & $0.3 \pm 0.2$ & $0.2 \pm 0.1$ \\
\hline
\end{tabular}

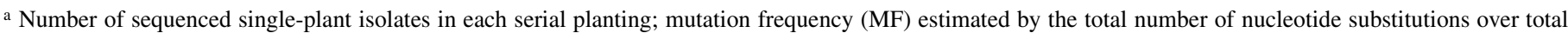
number of sequenced nucleotides; and nucleotide diversity $(\pi)$ and standard error estimated by the Kimura two-parameter model according to MEGA 3.1 (26).

b Not counted. 


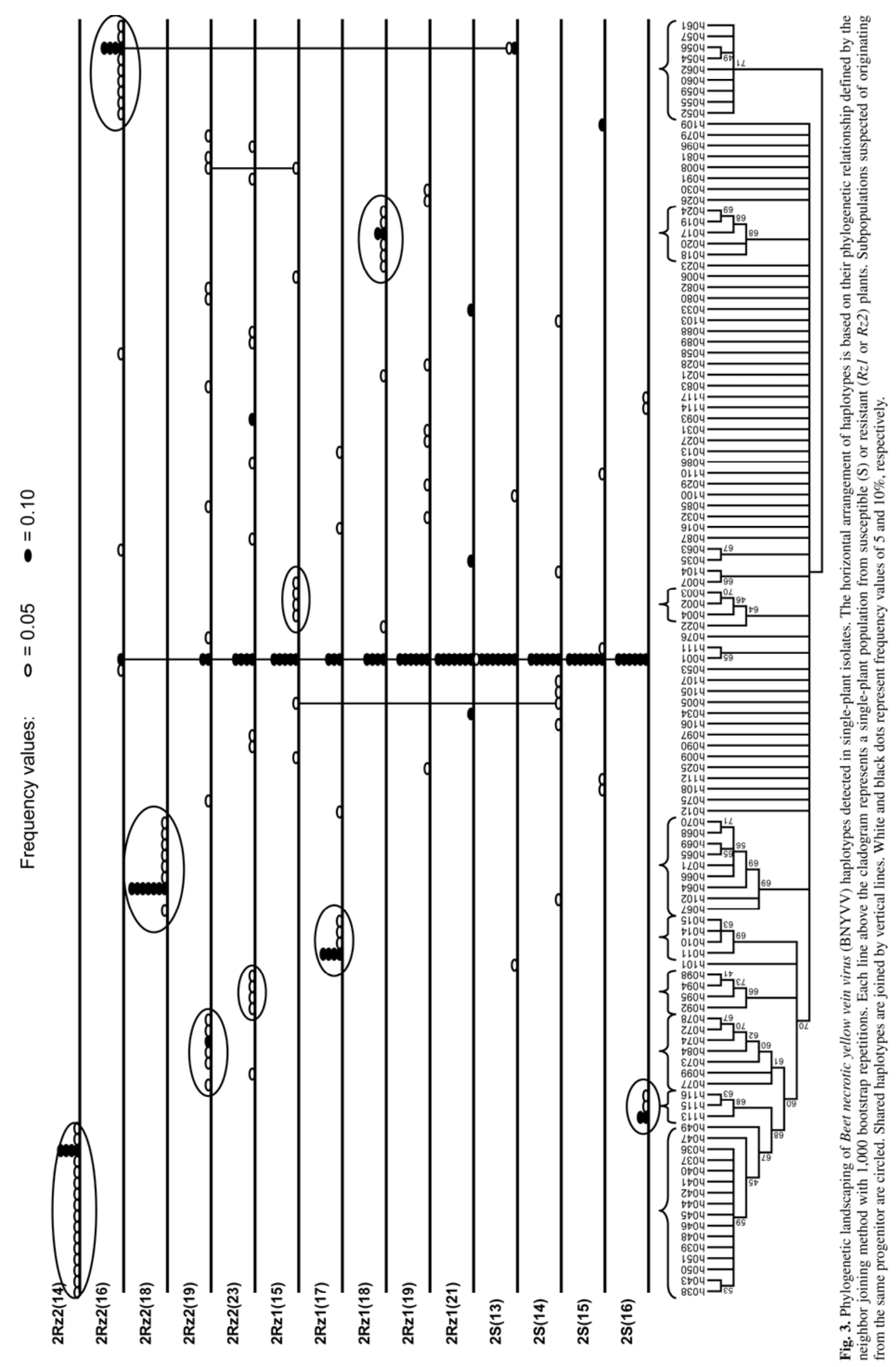


TABLE 4. Genetic diversity of single-plant Beet necrotic yellow vein virus consensus sequences in the field

\begin{tabular}{lcccl}
\hline $\begin{array}{l}\text { Host } \\
\text { genotype }\end{array}$ & $\begin{array}{c}\text { No. of } \\
\text { sequences }\end{array}$ & $\begin{array}{c}\text { Polymorphic } \\
\text { sites }\end{array}$ & $k \pm \mathrm{SE}^{\mathrm{a}}$ & $\begin{array}{c}\pi \pm \mathrm{SE} \\
\left(\times 10^{-3}\right)^{\mathrm{b}}\end{array}$ \\
\hline$R z 1$ & 15 & 5 & $0.99 \pm 0.2$ & $0.75 \pm 0.3$ \\
$R z 2$ & 15 & 12 & $2.64 \pm 0.4$ & $2.0 \pm 0.7$ \\
$\mathrm{~S}$ & 8 & 2 & $0.50 \pm 0.2$ & $0.38 \pm 0.2$ \\
\hline
\end{tabular}

a Average number of nucleotide differences \pm standard error (SE) estimated by DnaSP v4.10.7 (37).

${ }^{\mathrm{b}}$ Nucleotide diversity $(\pi)$ based on the Kimura $2 \mathrm{P}$ model \pm SE estimated by 500 replicates bootstrapping using MEGA 3.1 (26).

Similarly, the complexity of Hepatitis $C$ virus quasispecies is lower in patients with high virus titer than in those with low virus titer (30). Our results with BNYVV (Fig. 2) agree with these observations and represent the first confirmation of this relationship between fitness and diversity of a plant virus. However, at this point, we do not know if the population size per se or the underlying sugar beet resistance mechanism is the direct effector of increased BNYVV diversity in resistant plants.

Except for those viruses that are mechanically transmitted in the field $(7,36)$, limited data concerning the genetic structure of naturally transmitted plant virus populations are available. Moreover, in just a few cases, the populational genetic structure of a virus has been associated with one of its biological properties. For instance, natural infections of Citrus exocortis viroid in broad bean are generally asymptomatic and produce low viroid titers, high $\pi$ (0.026), and no predominant haplotypes (14). When one asymptomatic isolate was propagated by sap inoculation in broad bean after passage through tomato, its $\pi$ decreased to 0.001 , predominant haplotypes were identified, and plants developed severe symptoms and accumulated high viroid titers (15), which suggest a relationship between $\pi$ and virulence. Similarly, by analyzing composite samples of $R z l$ plants from the field (2), we found that avirulent BNYVV isolates were two to three times more genetically heterogeneous than those RB variants causing severe rhizomania. Nevertheless, at the interisolate level, $\pi$ was 4.8 times greater among RB than avirulent isolates. Similarly, in the present study, by consensus sequencing of single-plant isolates, we discovered that interisolate $\pi$ was 2.7 times greater among $R z 1$ than $R z 2$ plants (Table 4). Overall, the data support the idea that the genetic structure of virus populations is correlated with virulence and the level or type of host restrictions a virus has to overcome before causing a disease.

A direct link between BNYVV diversity and resistance breakdown by emerging RB variants was not evidenced in this study because none of the virus progenies evolved into RB variants after three serial plantings. Theoretically, a higher-than-usual virus genetic variability could drive virus populations into rapid adaptation or extinction by excessive accumulation of deleterious mutations $(12,16,31)$. In $R z 2$ plants, the greatest number of isolates accumulated more than one mutation in the sequenced RNA-3 regions and the fewest lineages survived by the third serial plantings (Fig. 1). These observations could suggest that, specifically in this incompatible BNYVV-Rz2 interaction, virus extinction rather than rapid host adaptation is a more likely outcome. However, if we take into consideration that BNYVV required more than 15 years to evidently defeat $R z l$ whereas severe rhizomania has been observed in $R z 2$ cultivars after a few crop cycles, the opposite outcome gets stronger support. Thus, altogether, the data suggest a direct positive relation between BNYVV diversification and speed of host adaptation that might be valid up to certain and still unknown limits on virus genetic variability.

\section{ACKNOWLEDGMENTS}

Funding of this work was provided from the Minnesota-North Dakota Research and Education Board, the Beet Sugar Development Foundation, and USDA-NRI grant no. 2008-35319-04472. We thank R. French (USDA-ARS), E. Mirkov (Texas A\&M University), J. M. Cuevas (Universidad de Valencia), and M. J. Smith (Texas AgriLife Research) for critical reading of the manuscript and their valuable suggestions; J. Arthur, A. Schwartz, and S. Acosta-Torres for their technical assistance; and F. Workneh and M. W. Fawley for their advice on statistics and population genetic analyses, respectively.

\section{LITERATURE CITED}

1. Acosta-Leal, R., Bryan, K. B., Smith, J. T., and Rush, C. M. 2009. Breakdown of host resistance by independent evolutionary lineages of Beet necrotic yellow vein virus involves a parallel $\mathrm{C} / \mathrm{U}$ mutation in its $p 25$ gene. Phytopathology 100:127-133.

2. Acosta-Leal, R., Fawley, M. W., and Rush, C. M. 2008. Changes in the intra-isolate genetic structure of Beet necrotic yellow vein virus populations associated with plant resistance breakdown. Virology 376:6068 .

3. Acosta-Leal, R., and Rush, C. M. 2007. Mutations associated with resistance-breaking isolates of Beet necrotic yellow vein virus and their allelic discrimination using TaqMan technology. Phytopathology 97:325330 .

4. Acosta-Leal, R., and Xiong, Z. 2008. Complementary functions of two recessive $R$-genes determine resistance durability of tobacco 'Virgin A Mutant' (VAM) to Potato virus Y. Virology 379:275-283.

5. Agudelo-Romero, P., de la Iglesia, F., and Elena, S. F. 2008. The pleiotropic cost of host-specialization in Tobacco etch potyvirus. Infect. Genet. Evol. 8:806-814.

6. Albiach-Marti, M. R., Guerri, J., de Mendoza, A. H., Laigret, F., Ballester-Olmos, J. F., and Moreno, P. 2000. Aphid transmission alters the genomic and defective RNA populations of Citrus tristeza virus isolates. Phytopathology 90:134-138.

7. Ayllón, M. A., Rubio, L., Moya, A., Guerri, J., and Moreno, P. 1999. The haplotype distribution of two genes of Citrus tristeza virus is altered after host change or aphid transmission. Virology 255:32-39.

8. Brlansky, R. H., Damsteegt, V. D., Howd, D. S., and Roy, A. 2003. Molecular analyses of Citrus tristeza virus subisolates separated by aphid transmission. Plant Dis. 87:397-401.

9. Burketová, L., Štillerová, K., and Feltlová, M. 2003. Immunohistological localization of chitinase and $\beta$-1,3-glucanase in rhizomania-diseased and benzothiadiazole treated sugar beet roots. Physiol. Mol. Plant Pathol. 63:47-54.

10. Cerni, S., Ruscic, J., Nolasco, G., Gatin, Z., Krajacic, M., and Skoric, D. 2008. Stem pitting and seedling yellows symptoms of Citrus tristeza virus infection may be determined by minor sequence variants. Virus Genes 36:241-249.

11. D’Urso, F., Ayllon, M. A., Rubio, L., Sambade, A., de Mendoza, A. H., Guerri, J., and Moreno, P. 2000. Contribution of uneven distribution of genomic RNA variants of Citrus tristeza virus (CTV) within the plant to changes in the viral population following aphid transmission. Plant Pathol. 49:288-294.

12. Elena, S. F., Agudelo-Romero, P., Carrasco, P., Codoner, F. M., Martin, S., Torres-Barcelo, C., and Sanjuán, R. 2008. Experimental evolution of plant RNA viruses. Heredity 100:478-483.

13. Excoffier, L., Laval, G., and Schneider, S. 2005. Arlequin ver. 3.0: an integrated software package for population genetics data analysis. Evol. Bioinf. Online 1:47-50.

14. Fagoaga, C., Semancik, J. S., and Duranvila, N. 1995. A Citrus exocortis viroid variant from broad bean (Vicia faba L.) -infectivity and pathogenesis. J. Gen. Virol. 76:2271-2277.

15. Gandia, M., Bernad, L., Rubio, L., and Duran-Vila, N. 2007. Host effect on the molecular and biological properties of a Citrus exocortis viroid isolate from Vicia faba. Phytopathology 97:1004-1010.

16. García-Arenal, F., Fraile, A., and Malpica, J. M. 2001. Variability and genetic structure of plant virus populations. Annu. Rev. Phytopathol. 39:157-186.

17. García-Arenal, F., Palukaitis, P., and Zaitlin, M. 1984. Strains and mutants of Tobacco mosaic virus are both found in virus derived from singlelesion-passaged inoculum. Virology 132:131-137.

18. Gibbs, A. J., Keese, P. L., Gibbs, M. J., and García-Arenal, F. 1999. Plant virus evolution: past, present, and future. Pages 263-285 in: Origin and Evolution of Viruses. E. Domingo, R. Webster, and J. J. Holland, eds. Academic Press, San Diego, CA.

19. Graur, D., and Li, W.-H. 2000. Fundamentals of Molecular Evolution, 2nd ed. Sinauer Associates, Inc., Sunderland, MA.

20. Hebrard, E., Pinel-Galzi, A., Bersoult, A., Sire, C., and Fargette, D. 2006. Emergence of a resistance-breaking isolate of Rice yellow mottle virus during serial inoculations is due to a single substitution in the genomelinked viral protein VPg. J. Gen. Virol. 87:1369-1373. 
21. Hugo, S. A., Henry, C. M., and Harju, V. 1996. The role of alternative host of Polymyxa betae in transmission of Beet necrotic yellow vein virus (BNYVV) in England. Plant Pathol. 45:662-666.

22. Jridi, C., Martin, J. F., Marie-Jeanne, V., Labonne, G., and Blanc, S. 2006. Distinct viral populations differentiate and evolve independently in a single perennial host plant. J. Virol. 80:2349-2357.

23. Jupin, I., Guilley, H., Richards, K. E., and Jonard, G. 1992. Two proteins encoded by Beet necrotic yellow vein virus RNA-3 influence symptom phenotype on leaves. EMBO J. 11:479-488.

24. Koenig, R., and Lennefors, B. L. 2000. Molecular analyses of European $\mathrm{A}, \mathrm{B}$ and $\mathrm{P}$ type sources of Beet necrotic yellow vein virus and detection of the rare P type in Kazakhstan. Arch. Virol. 145:1561-1570.

25. Koenig, R., Loss, S., Specht, S. J., Varrelmann, M., Lüddecke, P., and Deml, G. 2009. A single U/C nucleotide substitution changing alanine to valine in the Beet necrotic yellow vein virus P25 protein promotes increased virus accumulation in roots of mechanically inoculated, partially resistant sugar beet seedlings. J. Gen. Virol. 90:759-763.

26. Kumar, S., Tamura, K., and Nei, M. 2004. MEGA3: integrated software for molecular evolutionary genetics analysis and sequence alignment. Brief. Bioinform. 5:150-163.

27. Larson, R. L., Wintermantel, W. M., Hill, A., Fortis, L., and Nuñez, A. 2008. Proteome changes in sugar beet in response to Beet necrotic yellow vein virus. Physiol. Mol. Plant Pathol. 72:62-72.

28. Link, D., Schmidlin, L., Schirmer, A., Klein, E., Erhardt, M., Geldreich, A., Lemaire, O., and Gilmer, D. 2005. Functional characterization of the Beet necrotic yellow vein virus RNA-5-encoded $\mathrm{p} 26$ protein: evidence for structural pathogenicity determinants. J. Gen. Virol. 86:2115-2125.

29. Livak, K. J., and Schmittgen, T. D. 2001. Analysis of relative gene expression data using real-time quantitative PCR and $2^{-\Delta \Delta \mathrm{Ct}}$ method. Methods 25:402-408.

30. Mas, A., Ulloa, E., Bruguera, M., Furćić, I., Garriga, D., Fábregas, S., Andreu, D., Saiz, J. C., and Díez, J., 2004. Hepatitis C virus population analysis of a single-source nosocomial outbreak reveals an inverse correlation between viral load and quasispecies complexity. J. Gen. Virol. 85:3619-3626.

31. Moya, A., Holmes, E. C., and Gonzalez-Candelas, F. 2004. The population genetics and evolutionary epidemiology of RNA viruses. Nat. Rev. Microbiol. 2:279-288.

32. Pferdmenges, F., and Varrelmann, M. 2009. Breaking of Beet necrotic yellow vein virus resistance in sugar beet is independent of virus and vector inoculum densities. Eur. J. Plant Pathol. 124:231-245.

33. Rahim, M. D., Andika, I. B., Han, C., Kondo, H., and Tamada, T. 2007. RNA4-encoded p31of Beet necrotic yellow vein virus is involved in efficient vector transmission, symptom severity and silencing suppression in roots. J. Gen. Virol. 88:1611-1619.

34. Rico, P., Ivars, P., Elena, S. F., and Hernandez, C. 2006. Insights into the selective pressures restricting Pelargonium flower break virus genome variability: evidence for host adaptation. J. Virol. 80:8124-8132.

35. Rochon, D., Kakani, K., Robbins, M., and Reade, R. 2004. Molecular aspects of plant virus transmission by Olpidium and plasmodiophorid vectors. Annu. Rev. Phytopathol. 42:211-241.

36. Rodríguez-Cerezo, E., and García-Arenal, F. 1989. Genetic heterogeneity of the RNA genome population of the plant virus U5-TMV. Virology 170:418-423.

37. Rozas, J., Sánchez-DelBarrio, J. C., Messeguer, X., and Rozas, R. 2003. DnaSP, DNA polymorphism analyses by the coalescent and other methods. Bioinformatics 19:2496-2497.

38. Rush, C. M. 2003. Ecology and epidemiology of Benyviruses and plasmodiophorid vectors. Annu. Rev. Phytopathol. 41:567-592.

39. Rush, C. M., Liu, H.-Y., Lewellen, R. T., and Acosta-Leal, R. 2006. The continuing saga of rhizomania of sugar beets in the United States. Plant Dis. 90:4-15.

40. Sacristan, S., A. Fraile, J. M. Malpica, and F. Garcia-Arenal. 2005. An analysis of host adaptation and its relationship with virulence in Cucumber mosaic virus. Phytopathology 95:827-833.

41. Sambade, A., Ambros, S., Lopez, C., Ruiz-Ruiz, S., de Mendoza, A. H., Flores, R., Guerri, J., and Moreno, P. 2007. Preferential accumulation of severe variants of Citrus tristeza virus in plants co-inoculated with mild and severe variants. Arch. Virol. 152:1115-1126.

42. Schirmer, A., Link, D., Cognat, V., Moury, B., Beuve, M., Meunier, A., Bragard, C., Gilmer, D., and Lemaire, O. 2005. Phylogenetic analysis of isolates of Beet necrotic yellow vein virus collected worldwide. J. Gen. Virol. 86:2897-2911.

43. Schmidlin, L., De Bruyne, E., Weyens, G., Lefebvre, M., and Gilmer, D. 2008. Identification of differentially expressed root genes upon rhizomania disease. Mol. Plant Pathol. 9:741-751.

44. Scholten, O. E., and Lange, W. 2000. Breeding for resistance to rhizomania in sugar beet: a review. Euphytica 112:219-231.

45. Scholten, O. E., Paul, H., Peters, D., Van Lent, J. W. M., and Goldbach, R. W. 1994. In situ localization of Beet necrotic yellow vein virus (BNYVV) in rootlets of susceptible and resistant beet plants. Arch. Virol. 136:349361.

46. Tamada, T. 2002. Beet necrotic yellow vein virus. In: Descriptions of Plant Viruses. Available online by Assoc. Appl. Biol. www.dpvweb.net/dpv

47. Tamada, T., Uchino, H., Kusume, T., and Saito, M. 1999. RNA 3 deletion mutants of Beet necrotic yellow vein virus do not cause rhizomania disease in sugar beets. Phytopathology 89:1000-1006.

48. Tan, Z. Y., Gibbs, A. J., Tomitaka, Y., Sanchez, F., Ponz, F., and Ohshima, K. 2005. Mutations in Turnip mosaic virus genomes that have adapted to Raphanus sativus. J. Gen. Virol. 86:501-510.

49. Tuitert, G., Oorschot, M.-V., and Heijbroek, W. 1994. Effect of sugar beet cultivars with different levels of resistance to Beet necrotic yellow vein virus on transmission of virus by Polymyxa betae. Eur. J. Plant Pathol. 100:201-220.

50. Wright, S. 1965. The interpretation of population structure by F-statistics with special regard to systems mating. Evolution 19:395-420.

51. Yarwood, C. E. 1979. Host passage effects with plant viruses. Adv. Virus Res. 25:169-190. 